\title{
Potential Effect of Human Platelet Lysate on in vitro Expansion of Human Corneal Endothelial Cells Compared with Y-27632 ROCK Inhibitor
}

\author{
Mohammad Amir Mishan', MS; Sahar Balagholi ${ }^{2}$, PhD; Tahereh Chamani ${ }^{3}$, MS; Sepehr Feizi ${ }^{4}$, MD \\ Zahra-Soheila Soheili ${ }^{5}$, PhD; Mozhgan Rezaei Kanavi ${ }^{1}$, MD
}

\author{
${ }^{1}$ Ocular Tissue Engineering Research Center, Research Institute for Ophthalmology and Vision Science, Shahid Beheshti \\ University of Medical Sciences, Tehran, Iran \\ ${ }^{2}$ Blood Transfusion Research Center, High Institute for Research and Education in Transfusion Medicine, Tehran, Iran \\ ${ }^{3}$ Central Eye Bank of Iran, Tehran, Iran \\ ${ }^{4}$ Ophthalmic Research Center, Research Institute for Ophthalmology and Vision Science, Shahid Beheshti University of Medical \\ Sciences, Tehran, Iran \\ ${ }^{5}$ National Institute of Genetic Engineering and Biotechnology, Tehran, Iran \\ ORCID: \\ Mohammad Amir Mishan: https://orcid.org/0000-0001-8210-9322
}

Mozhgan Rezaei Kanavi: https://orcid.org/0000-0002-1497-2260

\section{Abstract}

Purpose: Corneal endothelial cell (CEC) therapy can be used as a promising therapeutic option for patients with various corneal endothelial dysfunctions. In this study, we compared the proliferative effect of human platelet lysate (HPL), as a xeno-free medium supplement, with Y-27632 Rho/rho-associated protein kinase (ROCK) inhibitor, as a wellknown proliferative and adhesive agent for CECs, and fetal bovine serum (FBS) as the control, in the culture medium of human corneal endothelial cells (HCECS).

Methods: We isolated HCECs from human donors and treated the cells as three different treatment groups including 20\% HPL only, $10 \mu \mathrm{M} \mathrm{Y}-27632$ ROCK inhibitor, combination of 20\% HPL and $10 \mu \mathrm{M} \mathrm{Y-27632} \mathrm{ROCK} \mathrm{inhibitor,} \mathrm{and} \mathrm{20 \%} \mathrm{FBS} \mathrm{as} \mathrm{the} \mathrm{control} \mathrm{group.} \mathrm{ELISA}$ cell proliferation assay and cell counting was performed on the treated cells. Finally, HCECs were characterized by morphology and immunocytochemistry (ICC).

Results: There was no significant proliferative effect of HPL on cell proliferation compared with the cells treated with Y-27632 ROCK inhibitor or the combination of HPL and Y-27632 ROCK inhibitor, but all the respected treatments had significant inducible effect on cell proliferation as compared with FBS-treated cells. The cells grown in all three treatment groups exhibited CEC morphology. Also, there was a higher expression of $\mathrm{Na}+/ \mathrm{K}+-\mathrm{ATP}$ ase and ZO-1, as CEC characteristic markers, in the culture of HCECs treated with HPL as compared with FBS.

Conclusion: HPL offers a xeno-free and affordable medium supplement for CEC expansion that can be used in clinical applications.

Keywords: Cell Proliferation; Corneal Endothelial Cells; Human Platelet Lysate; ROCK Inhibitor

J Ophthalmic Vis Res 2021; 16 (3): 349-356 


\section{INTRODUCTION}

Corneal endothelium plays a pivotal role in the corneal transparency by regulating the flow of water from the aqueous humor into cornea. ${ }^{[1]}$ Corneal endothelial cell (CEC) density is above 2000 cells $/ \mathrm{mm}^{2}$ in healthy people; however, corneal endothelial dysfunction and abnormal corneal hydration can occur following a decrease in CEC density to fewer than 400 cells $/ \mathrm{mm}^{2}$. [2] Loss of CECs also occurs as the result of Fuchs's endothelial corneal dystrophy (FECD) or following any form of corneal endothelial insult. ${ }^{[1]}$ Current treatments for these situations include penetrating keratoplasty (PKP) and endothelial keratoplasty techniques for replacing the damaged endothelial layer. $^{[3,4]}$ These surgical procedures are invasive and have several side effects. More importantly, there is a need for an alternative solution based on cell therapy and/or tissue engineering to overcome the global shortage of donor corneas. ${ }^{[5,6]}$ Therefore, cell therapy based on cultivated human corneal endothelial cells (HCECs) from cadaveric donor corneas has been suggested in several studies. ${ }^{[7,8]}$

Rho GTPases family plays a pivotal role at many aspects of cell cycle progression. ${ }^{[9]}$ It was shown that inhibition of Rho/Rho-associated protein kinase (ROCK) signaling by selective Y-27632 ROCK inhibitor could promote the proliferation of several primary adult cells ${ }^{[10-12]}$ and also the CECs. ${ }^{[13]}$ Moreover, ROCK inhibitors have been introduced for several diseases such as pulmonary disease, cardiovascular disease, and cancer. ${ }^{[14]}$ Among several techniques introduced for expansion and adhesion of CECs for clinical purposes, ${ }^{[15,16]}$ the use of ROCK inhibitors has become popular. ${ }^{[17,18]}$ On the other hand, the platelet-rich plasma (PRP) as an autologous

\section{Correspondence to:}

Mozhgan Rezaei Kanavi, MD. Ocular Tissue Engineering Research Center, Research Institute for Ophthalmology and Vision Science, Shahid Beheshti University of Medical Sciences, Tehran, Iran. No. 23, Paidarfard St., Boostan 9 St., Pasdaran Ave., Tehran 1666673111, Iran. E-mail: rezaeikanavi@gmail.com

Received: 30-01-2021 Accepted: 07-04-2021

\section{Access this article online}

Website: https://knepublishing.com/index.php/JOVR

DOI: 10.18502/jovr.v16i3.9431 blood product contains several growth factors and signaling molecules needed for tissue regeneration, and it has attracted researchers' attention in this field. ${ }^{[19-21]}$ The use of platelet lysate obtained from PRP, as a xeno-free and accessible medium supplement, has also gained popularity and can be used based on Good Manufacturing Practice (GMP) standards. $^{[22-24]}$

In this study, we aimed to investigate the effect of human platelet lysate (HPL) as a valuable source of growth factors on the proliferation behavior of HCECs as compared with Y-27632 ROCK inhibitor.

\section{METHODS}

To conduct the study, full ethical approval was obtained from the Institutional Review Board of the Central Eye Bank of Iran and the Ethics Committee of the Ophthalmic Research Center, Research Institute for Ophthalmology and Vision Science, Shahid Beheshti University of Medical Sciences, Tehran, Iran.

\section{Tissue Preparation}

Twelve human pre-stripped Descemet's membrane (DM) with CEC density of $>2500$ cells $/ \mathrm{mm}^{2}$ and preserved in Optisol-GS (Chiron Vision, Irvine, CA, USA) at $4^{\circ} \mathrm{C}$ were provided from the Central Eye Bank of Iran (Tehran, Iran). The corresponding donors were aged $26-50$ years and the death to preservation time was $<30 \mathrm{hr}$. The preparation of pre-stripped DM endothelial keratoplasty tissue at the Central Eye Bank of Iran has previously been described. ${ }^{[25]}$ Briefly, after making a circumferential incision to the trabecular meshwork, without the use of dye or trephine, the edge of the DM from one side was gently grasped and peeled toward the opposite side and then transferred to OptisolGS at $4^{\circ} \mathrm{C}$.

This is an open access journal, and articles are distributed under the terms of the Creative Commons Attribution-NonCommercial-ShareAlike 4.0 License, which allows others to remix, tweak, and build upon the work non-commercially, as long as appropriate credit is given and the new creations are licensed under the identical terms.

How to cite this article: Mishan MA, Balagholi S, Chamani T, Feizi S, Soheili ZS, Kanavi MR. Potential Effect of Human Platelet Lysate on in vitro Expansion of Human Corneal Endothelial Cells Compared with Y-27632 ROCK Inhibitor. J Ophthalmic Vis Res 2021;16:349-356. 


\section{Human Platelet Lysate (HPL) Preparation}

PRPs were provided from Iranian Blood Transfusion Organization (Tehran, Iran). The samples were pooled from three different healthy donors with a platelet count of $2.4 \times 10^{5} / \mu \mathrm{l}$. HPL was obtained according to the repeated freeze-thaw method. ${ }^{[26]}$ Accordingly, the pooled PRPs were kept at $-80^{\circ} \mathrm{C}$ for $24 \mathrm{hr}$, then thawed at $37^{\circ} \mathrm{C}$ in a water bath for 1 $\mathrm{hr}$, and this action was repeated three times. After that, the solution was centrifuged at $2000 \mathrm{~g}$ for 10 min to remove the debris. Finally, the supernatant containing HPL was filtered using a $0.2 \mu \mathrm{m}$ sterile filter.

\section{Isolation and Culture of HCECs}

Our experiment on cultivated HCECs was composed of two main parts (ELISA in part one and cell counting, morphology, and immunocytochemistry [ICC] in the second part). Each part was performed in triplicate. For each run, the DMs from six different cornea donors were pooled and incubated in $3.5 \mathrm{mg} / \mathrm{ml}$ collagenase A (Roche, USA) at $37^{\circ} \mathrm{C}$ for $50 \mathrm{~min}$ and then centrifuged at $300 \mathrm{~g}$ for $5 \mathrm{~min}$. Finally, the pooled cells were cultured in DMEM: F12 supplemented with 20\% fetal bovine serum (FBS; Gibco), 120 $\mathrm{mg} / \mathrm{ml}$ penicillin (Sigma, Germany), and $220 \mathrm{mg} / \mathrm{ml}$ streptomycin (Sigma, Germany) on a 24-well plate coated with $20 \mathrm{mg} / \mathrm{ml}$ of fibronectin (Sigma, USA) at $37^{\circ} \mathrm{C}$ and $5 \% \mathrm{CO}_{2}$. All experiments were performed when the cells were in P1. For this purpose, after two weeks of cell isolation and culture, the cells were passaged by trypsin/EDTA and seeded on a 24-well plate at a seeding density of $1 \times 10^{4}$ cells per well with DMEM: F12 culture medium supplemented with three different treatment groups including 20\% HPL, $10 \mu \mathrm{M} \mathrm{Y}$ 27632 ROCK inhibitor (STEMCELL Technologies, USA), combination of 20\% HPL and $10 \mu \mathrm{M}$ Y-27632 ROCK inhibitor, and $20 \%$ FBS as the control group. The concentration of Y-27632 ROCK inhibitor was designated based on the previous studies. ${ }^{[18,27,28]}$

\section{ELISA Cell Proliferation Assay}

HCECs were seeded on 96-well plates at 5000 cells/well in $200 \mu \mathrm{l}$ culture medium. The culture medium in each well was first changed with $100 \mathrm{ml}$ of DMEM: F12 1:1 and then supplemented with 20\%
HPL, $10 \mu \mathrm{M}$ Y-27632 ROCK inhibitor, combination of $20 \%$ of HPL and $10 \mu \mathrm{M} \mathrm{Y-27632} \mathrm{ROCK} \mathrm{inhibitor,}$ and 20\% FBS (control group). To determine whether the HPL and/or Y-27632 ROCK inhibitor altered cell proliferation, bromodeoxyuridine (BrdU) was added after $24 \mathrm{hr}$ of treatment and the proliferation assay was performed according to the manufacturer's instructions (Roche Diagnostic, Mannheim, Germany). An ELISA reader (ELX 808 Absorbance Reader, BioTek Instruments, Winooski, VT) was implemented to read the absorption of the investigated samples at specified wavelengths.

\section{Cell Counting}

To assess HCECs proliferation after treatments, phase contrast micrographs at $\times 100$ magnification of three random photos were recorded and the number of cells were counted using ImageJ software (National Institutes of Health) and then averaged. ${ }^{[29]}$

\section{HCECs Characterization}

The characteristics of the cultured HCECs were verified based on the morphology and the expression of molecular markers. Polygonal/hexagonal appearance as the characteristic of CECs, was used to differentiate these cells from human corneal stromal fibroblasts with spindle-shaped appearance (Olympus IX71, Tokyo, Japan). Also, the expression of the molecular markers was detected using ICC.

\section{Immunocytochemistry (ICC)}

Two groups of treatments, the cultured HCECs with $20 \% \mathrm{HPL}$ and $20 \% \mathrm{FBS}$, in a 24-well plate were fixed by incubating in $-10^{\circ} \mathrm{C}$ methanol for $10 \mathrm{~min}$. Then, the cells were permeabilized using Triton X-100 (0.25\%) and blocked in 1\% bovine serum albumin (BSA) in PBS for $1 \mathrm{hr}$ at room temperature. The expressions of $\mathrm{Na}^{+} / \mathrm{K}^{+}$ATPase, zonula occludens-1 (ZO-1) and vimentin were detected at protein levels by 1:500 of primary Rabbit anti-Human $\mathrm{Na}^{+} / \mathrm{K}^{+}$-ATPase (Santa Cruz Biotechnology Inc., Dallas, USA, sc-28800) and 1:400 of primary Rabbit anti-Human ZO-1 (Santa Cruz Biotechnology Inc., Dallas, USA, sc-10804) for 90 min each, and 1:800 of primary Rabbit antiHuman vimentin (Santa Cruz Biotechnology Inc., 
Dallas, USA, sc-5565) for $60 \mathrm{~min}$. Thereafter, the slides were incubated with 1:200 of goat anti-rabbit IgG-fluorescein isothiocyanate (FITC) conjugated antibody (Santa Cruz Biotechnology Inc., Dallas, USA, sc-2012) for $45 \mathrm{~min}$ in darkness and at room temperature. After washing with PBS, the slides were counterstained with $1.5 \mathrm{mg} / \mathrm{ml}$ of 4,6 diamidino-2-phenyindole dihydrochloride (DAPI, Santa Cruz, USA) for $10 \mathrm{~min}$. The images were then captured using a fluorescence microscope (Olympus IX71, Tokyo, Japan) equipped with a digital camera (Olympus U-TVO.63XC; Tokyo, Japan) and an excitation wavelength of 450$520 \mathrm{~nm}$. ImageJ software (ImageJ 1.48; National Institute of Health; http://rsb.info.nih.gov/ij/) was used to quantify the corrected total cellular fluorescence (CTCF) per image and the mean values were compared between the HPL-treated and FBS, as the control cells.

\section{Statistical Analysis}

Data were quantitatively compared between the treated groups using one-way ANOVA and Tukey's multiple comparison test for ELISA cell proliferation assay and cell counting, and t-test for CTCF analysis by the Graph Pad Prism (version 6.0). Results were expressed as the means \pm standard deviation (SD) obtained from three independent experiments.

\section{RESULTS}

\section{Cell Proliferation Assay}

HPL at $20 \%$ concentration significantly increased the cell proliferation rate compared with the control cultures in 20\% FBS-containing medium. However, the proliferation of cultured HCECs after $24 \mathrm{hr}$ treatment with HPL was similar to those treated with Y-27632 ROCK inhibitor and also with combination of HPL and Y-27632 ROCK inhibitor. Besides, Y-27632 ROCK in a concentration of 10 $\mu \mathrm{M}$ significantly increased HCECs as compared to $20 \%$ FBS control [Figure 1].

\section{Cell Counting}

After one and five days, the number of cells was recorded from respected photos using ImageJ software and results showed that the cell numbers were significantly higher in all three treatment groups compared with FBS as the control group, at both time points as shown in Figure 2 .

\section{Morphology}

The morphologies of cultured HCECs in DMEM/F12 medium supplemented with all three treatment groups and FBS as the control are shown in Figure 3. Polygonal/hexagonal shape, characteristics of CECs, were observed in the cultures, as it was confirmed with immunostaining for $\mathrm{Na}+/ \mathrm{K}+-\mathrm{ATP}$ ase [Figure 4D] and ZO-1 [Figure 4E] markers. The cells reached over $80 \%$ confluency after five days of culture.

\section{Immunocytochemistry (ICC)}

The ICC results revealed that the cultivated cells were immune reactive for $\mathrm{Na}+/ \mathrm{K}+$-ATPase [Figure 4D] and ZO-1 [Figure 4E] markers, confirming the identity of the cultured cells as CECs. $\mathrm{Na}+/ \mathrm{K}+-$ ATPase expression was detected in approximately $100 \%$ of the HCECs, and $>94 \%$ and $>98 \%$ of the HCECs expressed ZO-1 and vimentin, respectively. CTCF results showed higher expressions of the HCECs for $\mathrm{Na}+/ \mathrm{K}+-A T P a s e$ [Figure 4G] and ZO-1 [Figure $4 \mathrm{H}$ ] proteins in $20 \%$ HPL-treated HCECs as compared to the FBS- treated (control) group. Also, means of CTCF for vimentin expression were not significantly different between the two groups [Figure 4I]. Taken together, these results indicate that the cells expressed the original characteristics of CECs. The negative controls without primary antibody did not show any FITC reactivity (data were not shown).

\section{DISCUSSION}

The results of this study indicate that HCECs gained a potential proliferation after treatment with $20 \% \mathrm{HPL}$ in comparison with FBS as the control group although this proliferation effect was comparable to that in the Y-27632 ROCK inhibitortreated group. To the best of our knowledge, there is no published investigation comparing the effects of HPL with Y-27632 ROCK inhibitor on HCECs culture. Given that HPL can be of GMP grade and is a cost-benefit supplement for cell culture, it can be a superior proliferative agent for in vitro expansion of HCECs for therapeutic goals. 


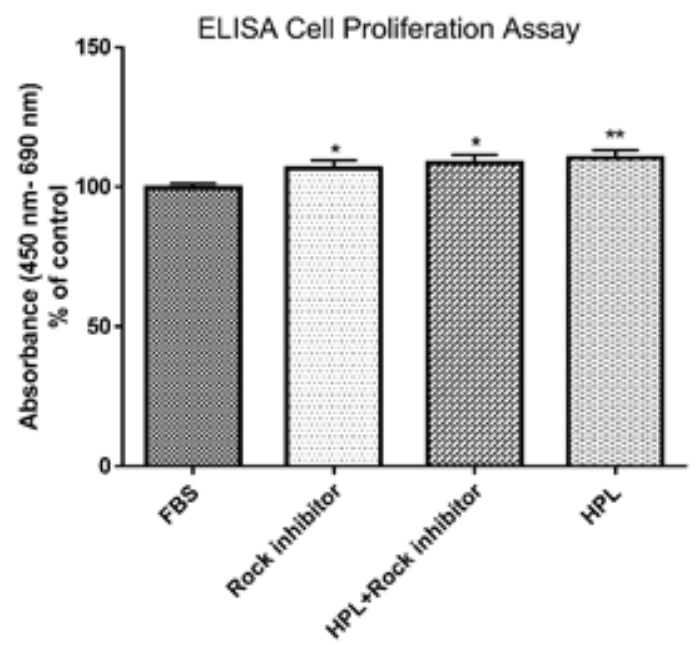

Figure 1. Cell proliferation assay. Results show a higher proliferative effect of all treatment groups as compared to the control group $\left({ }^{*} P<0.05\right.$ and $\left.{ }^{* *} P<0.01\right)$.
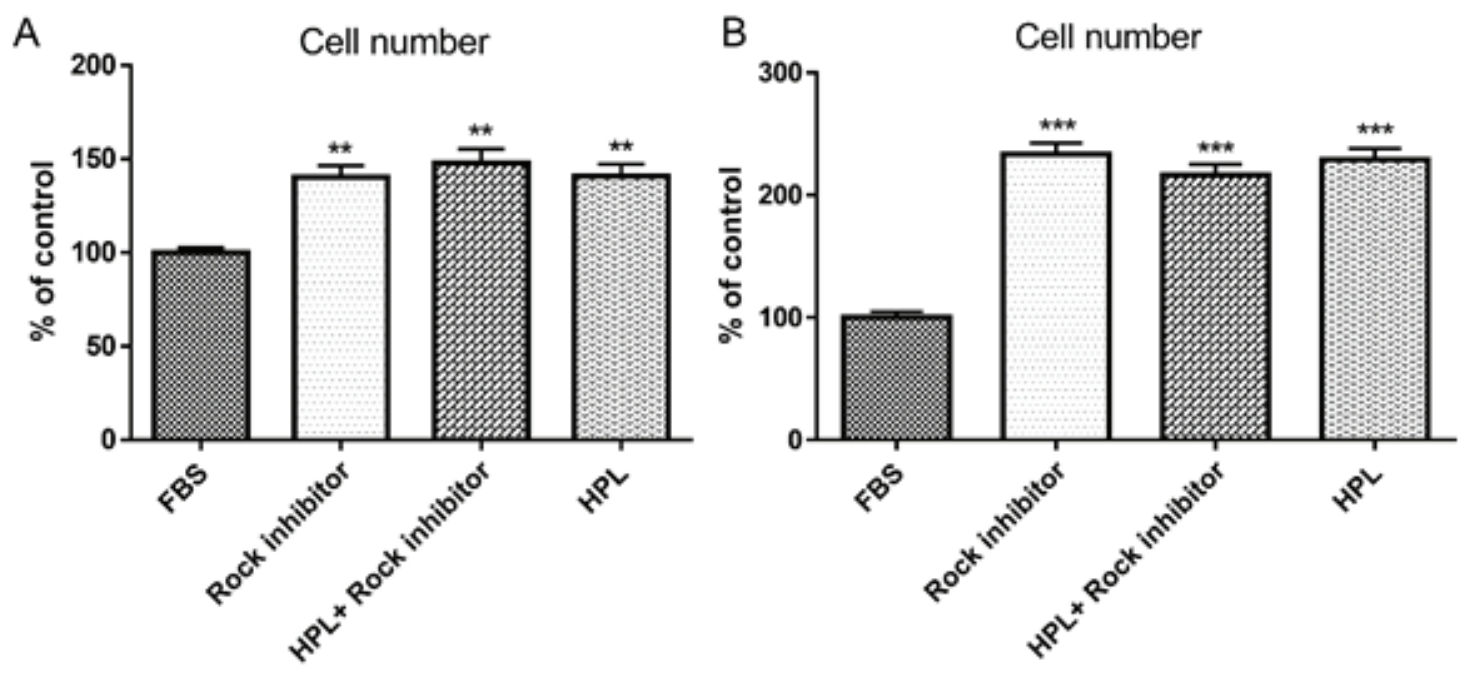

Figure 2. The numbers of HCECs after $(A)$ one and $(B)$ five days of treatments. As illustrated, the numbers of HCECs treated with HPL, combination of HPL and Y-27632 ROCK inhibitor, and Y-27632 ROCK inhibitor alone was significantly higher than FBS (control)-treated group $\left({ }^{* *} P<0.01\right.$ and $\left.{ }^{* * *} P<0.001\right)$.

More importantly, HPL was provided using a freeze/thaw method in the current study. It was previously demonstrated that this method ensures maximum release of growth factors and cytokines from the platelet compartment, providing enrichment of growth factors such as platelet-derived growth factor (PDGF)-AB/BB, platelet factor-4, epidermal growth factor (EGF), transforming growth factor (TGF)- $\beta 1$, and fibroblast growth factor (FGF)-2. ${ }^{[30]}$

The proliferative potential of $\mathrm{HPL}$, as an alternative to FBS, has been demonstrated for various primary cells to avoid risk of zoonosis for cell banking and clinical purposes. ${ }^{[31,32]}$ In addition, it was demonstrated that bovine CECs expanded in platelet releasate had good intercellular adhesion together with hexagonal morphologies. ${ }^{[33]}$ In another study, it was observed that all three different HPLs prepared via different ways induced proliferation of the BCE C/D-1b cells as a bovine CEC line, without noticeable differences compared to $10 \%$ FBS. $^{[34]}$ Therefore, HPL has been introduced as a xeno-free supplement for culturing $\mathrm{CECS}^{[16]}$ and according to the results of our study, HPL 

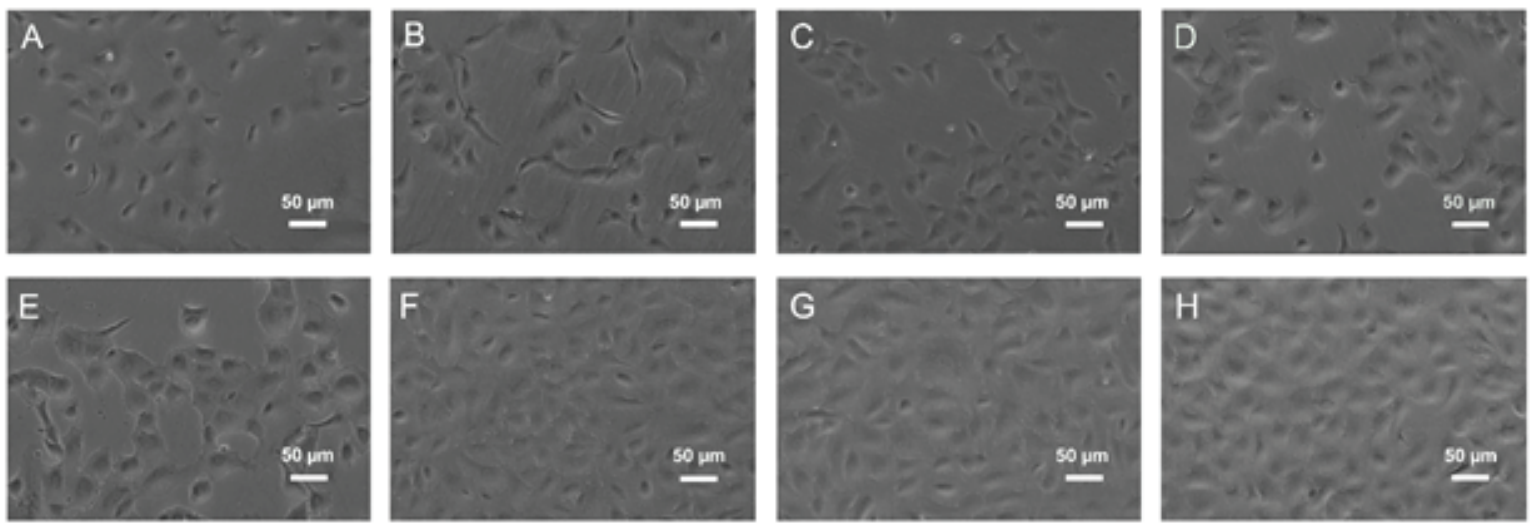

Figure 3. Representative photomicrographs of cultivated HCECs in treated and control groups (A-D) one and (E-H) five days after treatments. The morphology of HCECs after five days of cultures in (E) 20\% FBS, (F) $10 \mu \mathrm{M} \mathrm{Y-27632} \mathrm{ROCK} \mathrm{inhibitor,} \mathrm{(G)} \mathrm{combination}$ of $20 \% \mathrm{HPL}$ and $10 \mu \mathrm{M}$ Y-27632 ROCK inhibitor, and $(\mathrm{H}) 20 \% \mathrm{HPL}$.
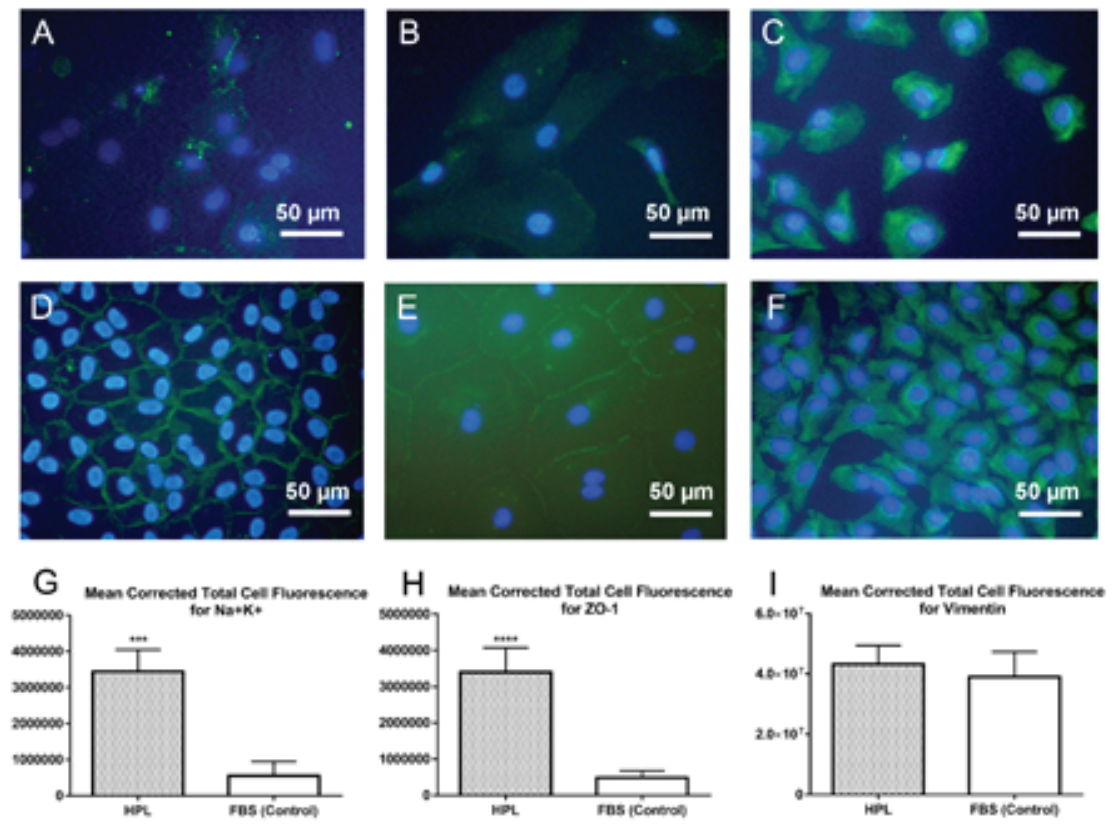

Figure 4. Expression of Na+/K+-ATPase, ZO-1 and vimentin proteins in the HCECs cultured in $20 \%$ HPL and $20 \%$ FBS, as the control group, after five days of treatments. (A) A merged FITC-Na+/K-ATPase antibody and DAPI image in the cells treated with 20\% FBS. (B) A merged FITC-ZO-1 antibody and DAPI image in the cells treated with 20\% FBS. (C) A merged FITC- vimentin antibody and DAPI image in the cells treated with $20 \%$ FBS. (D) A merged FITC-Na+/K-ATPase antibody and DAPI image in the cells treated with 20\% HPL. (E) A merged FITC-ZO-1 antibody and DAPI image in the cells treated with $20 \% \mathrm{HPL}$. (F) A merged FITC-vimentin antibody and DAPI image in the cells treated with 20\% HPL. Mean CTCF values of (G) Na+/K+-ATPase and (H) ZO-1 protein expressions show a significant increase in the HPL-treated HCECs as compared to the control group ( $^{* * *} P<0.001$ and ${ }^{* * * *} P<0.0001$, respectively). (I) Means of CTCF for vimentin expression were not significantly different between the two groups.

induces a higher proliferative effect on the expansion of HCECs than FBS.

ROCK signaling pathway is involved in the regulation of important cellular functions including cytoskeleton organization, cell proliferation and migration, ${ }^{[35,36]}$ and initiation of apoptotic signaling pathways in stressful conditions. ${ }^{[37,38]}$ Also, this signaling pathway negatively regulates cell adhesion through actin depolymerization inhibition; however, it was demonstrated that inhibition of ROCK by Y-27632 agent promotes actin reorganization and results in CEC adhesion 
induction. ${ }^{[8,13]}$ More studies have suggested that Y-27632 ROCK inhibitor is a safe and effective additive agent for expansion of CECs. ${ }^{[7,13,28,39]}$ Interestingly, it was observed that Y-27632 improved the attachment and proliferation of HCECs isolated from young donors; however, these effects were not observed in HCECs isolated from older donors aged 60 and above. ${ }^{[18]}$ This may be due to the increase of cyclin kinase inhibitors $\mathrm{p} 16^{\mathrm{INK} 4 \mathrm{a}}$ and $\mathrm{p} 21^{\mathrm{WAF} 1 / \mathrm{Cip} 1}$ that results in an age-dependent increase in negative regulation of cell cycle. ${ }^{[40]}$ In the current study, although Y-27632 ROCK inhibitor exerted an elevated proliferation of HCECs in culture as compared with the control group, its effect was not superior to that of $20 \%$ HPL. Surprisingly, the combination of HPL and Y-27632 ROCK inhibitor had a similar effect on cell proliferation compared with Y-27632 ROCK or HPL alone. Further investigation will be required to verify the proposed statement.

In addition to the superior effects of the HPL over FBS on the cell proliferation, this natural PRP-derived supplement has also other advantages. It can be prepared simply as an autologous blood product from the recipients of HCECs allografts, which may be of great importance in reducing the risk of rejection and the need for immune suppression strategies. ${ }^{[41,42]}$ Moreover, given that PRP is an ideal source of autologous growth factors, ${ }^{[41]}$ it can be a proper agent for corneal endothelial tissue engineering and cell-based therapies in near future.

In conclusion, HCECs culture data showed a higher proliferation rate in the cells treated with 20\% HPL in comparison to those treated with FBS. On the other hand, the effects of $\mathrm{HPL}$ on the proliferation of the HCECs were comparable with Y-27632 ROCK inhibitor alone and with the combination of HPL and Y-27632 ROCK inhibitor. Therefore, HPL can be used as a cost-benefit and xeno-free supplement in the culture of HCECs rather than Y-27632 ROCK inhibitor or FBS. Other advantages of HPL are its autologous and GMP grade characteristics that can ensure its safety in future clinical cellbased therapies. However, further investigations based on animal models and clinical trials are needed to elucidate the efficacy of HPL in comparison with Y-27632 ROCK inhibitor in vivo.

\section{Acknowledgements}

The authors express their gratitude to the Central Eye Bank of Iran for providing the donor eyes.

\section{Financial Support and Sponsorship}

The manuscript was funded by Shahid Beheshti University of Medical Sciences (Grant Number: 15739-5).

\section{Conflicts of Interest}

All authors declare that they have no conflicts of interests.

\section{REFERENCES}

1. Dawson DG, Ubels JL, Edelhauser HF. Cornea and sclera. In: Levin LA, Nilsson SFE, Ver Hoeve J, Wu SM, editors. Adler's physiology of the eye. Elsevier; 2011.

2. Bourne WM. Clinical estimation of corneal endothelial pump function. Trans Am Ophthalmol Soc 1998;96:229242.

3. Tan DT, Dart JK, Holland EJ, Kinoshita S. Corneal transplantation. Lancet 2012;379:1749-1761.

4. Gain P, Jullienne R, He Z, Aldossary M, Acquart S, Cognasse $F$, et al. Global survey of corneal transplantation and eye banking. JAMA Ophthalmol 2016;134:167-173.

5. Parekh M, Ahmad S, Ruzza A, Ferrari S. Human corneal endothelial cell cultivation from old donor corneas with forced attachment. Sci Rep 2017;7:142.

6. Nuzzi R, Marolo P, Tridico F. From DMEK to corneal endothelial cell therapy: technical and biological aspects. J Ophthalmol 2018;2018: 6482095.

7. Kinoshita $\mathrm{S}$, Koizumi $\mathrm{N}$, Ueno $\mathrm{M}$, Okumura $\mathrm{N}$, Imai $\mathrm{K}$, Tanaka $\mathrm{H}$, et al. Injection of cultured cells with a ROCK inhibitor for bullous keratopathy. $N$ Engl J Med 2018;378:995-1003.

8. Okumura N, Koizumi N, Ueno M, Sakamoto $\mathrm{Y}$, Takahashi $H$, Tsuchiya $H$, et al. ROCK inhibitor converts corneal endothelial cells into a phenotype capable of regenerating in vivo endothelial tissue. Am J Pathol 2012;181:268-277.

9. Coleman ML, Marshall CJ, Olson MF. RAS and RHO GTPases in G1-phase cell-cycle regulation. Nat Rev Mol Cell Biol 2004;5:355-366.

10. Sun CC, Chiu HT, Lin YF, Lee KY, Pang JHS. Y-27632, a ROCK inhibitor, promoted limbal epithelial cell proliferation and corneal wound healing. PLoS One 2015;10:e0144571.

11. Chapman S, McDermott DH, Shen K, Jang MK, McBride $A A$. The effect of Rho kinase inhibition on long-term keratinocyte proliferation is rapid and conditional. Stem Cell Res Ther 2014;5:60.

12. Wang T, Kang W, Du L, Ge S. Rho-kinase inhibitor Y-27632 facilitates the proliferation, migration and pluripotency of human periodontal ligament stem cells. J Cell Mol Med 2017;21:3100-3112. 
13. Okumura N, Ueno M, Koizumi N, Sakamoto $\mathrm{Y}$, Hirata $\mathrm{K}$, Hamuro J, et al. Enhancement on primate corneal endothelial cell survival in vitro by a ROCK inhibitor. Invest Ophthalmol Vis Sci 2009;50:3680-3687.

14. Liao JK, Seto M, Noma K. Rho kinase (ROCK) inhibitors. J Cardiovasc Pharmacol 2007;50:17-24.

15. Feizi S, Soheili ZS, Bagheri A, Balagholi S, Mohammadian A, Rezaei-Kanavi M, et al. Effect of amniotic fluid on the in vitro culture of human corneal endothelial cells. Exp Eye Res 2014;122:132-140.

16. Thieme D, Reuland L, Lindl T, Kruse F, Fuchsluger T. Optimized human platelet lysate as novel basis for a serum-, xeno-, and additive-free corneal endothelial cell and tissue culture. J Tissue Eng Regen Med 2018;12:557564.

17. Okumura N, Sakamoto Y, Fujii K, Kitano J, Nakano S, Tsujimoto $Y$, et al. Rho kinase inhibitor enables cellbased therapy for corneal endothelial dysfunction. Sci Rep 2016;6:26113.

18. Peh GS, Adnan K, George BL, Ang HP, Seah XY, Tan DT, et al. The effects of Rho-associated kinase inhibitor Y-27632 on primary human corneal endothelial cells propagated using a dual media approach. Sci Rep 2015;5:9167.

19. Sample SJ, Racette MA, Hans EC, Volstad NJ, Schaefer $\mathrm{SL}$, Bleedorn JA, et al. Use of a platelet-rich plasmacollagen scaffold as a bioenhanced repair treatment for management of partial cruciate ligament rupture in dogs. PloS One 2018;13:e0197204.

20. Spanò R, Muraglia A, Todeschi MR, Nardini M, Strada P, Cancedda $\mathrm{R}$, et al. Platelet-rich plasma-based bioactive membrane as a new advanced wound care tool. J Tissue Eng Regen Med 2018;12:e82-e96.

21. Fernandes G, Yang S. Application of platelet-rich plasma with stem cells in bone and periodontal tissue engineering. Bone Res 2016;4:16036.

22. Naskou MC, Sumner SM, Chocallo A, Kemelmakher H, Thoresen M, Copland I, et al. Platelet lysate as a novel serum-free media supplement for the culture of equine bone marrow-derived mesenchymal stem cells. Stem Cell Res Ther 2018;9:75.

23. Švajger U. Human platelet lysate is a successful alternative serum supplement for propagation of monocyte-derived dendritic cells. Cytotherapy 2017;19:486-499.

24. Saury C, Lardenois A, Schleder C, Leroux I, Lieubeau B, David L, et al. Human serum and platelet lysate are appropriate xeno-free alternatives for clinical-grade production of human MuStem cell batches. Stem Cell Res Ther 2018;9:128.

25. Chamani T, Javadi MA, Kanavi MR. Trephine-and dyefree technique for eye bank preparation of pre-stripped Descemet membrane endothelial keratoplasty tissue. Cell Tissue Bank 2019;20:321-326.

26. Şeker Ş, Elçin AE, Elçin YM. Autologous protein-based scaffold composed of platelet lysate and aminated hyaluronic acid. J Mater Sci Mater Med 2019;30:127.

27. Su CC, Chen CW, Ho WT, Hu FR, Lee SH, Wang IJ. Phenotypes of trypsin-and collagenase-prepared bovine corneal endothelial cells in the presence of a selective Rho kinase inhibitor, Y-27632. Mol Vis 2015;21:633-643.

28. Pipparelli A, Arsenijevic Y, Thuret G, Gain P, Nicolas M, Majo F. ROCK inhibitor enhances adhesion and wound healing of human corneal endothelial cells. PloS One 2013;8:e62095.

29. Rasband WS. ImageJ. Bethesda, Maryland, USA: National Institutes of Health; 1997-2016.

30. Strandberg G, Sellberg F, Sommar P, Ronaghi $M$, Lubenow N, Knutson F, et al, Standardizing the freezethaw preparation of growth factors from platelet lysate. Transfusion 2017;57:1058-1065.

31. Carducci A, Scafetta G, Siciliano C, Carnevale R, Rosa P, Coccia A, et al. GMP-grade platelet lysate enhances proliferation and migration of tenon fibroblasts. Front Biosci 2016;8:84-99.

32. Burnouf T, Strunk D, Koh MB, Schallmoser K. Human platelet lysate: replacing fetal bovine serum as a gold standard for human cell propagation? Biomaterials 2016;76:371-387.

33. Chou ML, Burnouf T, Wang TJ. Ex vivo expansion of bovine corneal endothelial cells in xeno-free medium supplemented with platelet releasate. PloS One 2014;9:e99145.

34. Wang TJ, Chen MS, Chou ML, Lin HC, Seghatchian J, Burnouf T. Comparison of three human platelet lysates used as supplements for in vitro expansion of corneal endothelium cells. Transfus Apher Sci 2017;56:769-773.

35. Olson MF, Ashworth A, Hall A. An essential role for Rho, Rac, and Cdc42 GTPases in cell cycle progression through G1. Science 1995;269:1270-1272.

36. Coleman ML, Olson MF. Rho GTPase signalling pathways in the morphological changes associated with apoptosis. Cell Death Differ 2002;9:493-504.

37. Riento K, Ridley AJ. Rocks: multifunctional kinases in cell behaviour. Nat Rev Mol Cell Biol 2003;4:446-456.

38. Amano M, Fukata $Y$, Kaibuchi K. Regulation and functions of Rho-associated kinase. Exp Cell Res 2000;261:44-51.

39. Okumura N, Koizumi N, Ueno M, Sakamoto Y, Takahashi $\mathrm{H}$, Hamuro J, et al. The new therapeutic concept of using a rho kinase inhibitor for the treatment of corneal endothelial dysfunction. Cornea 2011;30:S54-S59.

40. Enomoto K, Mimura T, Harris DL, Joyce NC. Age differences in cyclin-dependent kinase inhibitor expression and rb hyperphosphorylation in human corneal endothelial cells. Invest Ophthalmol Vis Sci 2006;47:4330-4340.

41. Sánchez M, Anitua E, Delgado D, Sanchez P, Prado R, Orive $\mathrm{G}$, et al., Platelet-rich plasma, a source of autologous growth factors and biomimetic scaffold for peripheral nerve regeneration. Expert Opin Biol Ther 2017;17:197212.

42. Vis PW, Bouten CV, Sluijter JP, Pasterkamp G, van Herwerden LA, Kluin J. Platelet-lysate as an autologous alternative for fetal bovine serum in cardiovascular tissue engineering. Tissue Eng Part A 2010;16:1317-1327. 